\title{
CONCEPTUAL FRAMEWORK OF INTERNATIONAL COOPERATION TO COUNTER UNCONVENTIONAL THREATS
}

\author{
Sergiu-Mihai IONIȚĂ $\breve{A}^{27}$
}

\begin{abstract}
Unconventional threats to the security climate in South-Eastern Europe and, specifically oriented on states openly engaged in the fight against international terrorism, organized crime and the proliferation of WMD (weapons of mass destruction) will persist due to logistical disparities between states. Regarding common work, aimed at applying juridic international framework, in the field of fighting terrorism, in the field of countering crime, measures such as cutting terrorism financing, denying access of terrorist groups to biologic and chemical substances, devices or nuclear technologies, communication systems are a common necessity for all nowadays democratic countries.

In this paper, our research focuses on the analysis of the extended framework of international cooperation for counterting unconventional threats and on detailing the modalities of informative and police cooperation in the field of contemporary unconventional threats.

Keywords: security, cooperation, threats, terrorism, organized crime, prevention, countering.
\end{abstract}

Within the European Union, different ways are available facilitating law enforcement cooperation between member states. This category includes cooperation protocols between Europol and Eurojust for instance, and other normative acts regarding the exchange of information, as well as those on the Joint Investigation Group establishment. All these regulations provide a solid basis giving the European Union powerful means to fight against organized crime.

It must be said, however, that effectiveness of legislative instruments is diminished by the lack of an overall framework and methodology to allow Member States to adopt a common working approach. The different approach between the Member States and the EU institutions can lead to an increase of efforts, to the inefficient use of the available cooperation means in providing the opportunity to solve - common priority issues. Analyzing these issues, the London Conference of 19-20 May 2005 on cooperation in the field of information, ended with the following conclusions:

- it admits the importance of improving knowledge and understanding of the concept of international threat in response to streamlining the law enforcement process;

- it acknowledges that a number of ways are available at EU level facilitating law enforcement cooperation between Member States, including

\footnotetext{
${ }^{27}$ Lieutenant, Special Telecommunication Service, $\mathrm{PhD}$ candidate.
} 
interinstitutional protocols, legislative regulations and intergovernmental agreements that have created the framework for the exchange of information; analyses that the effective implementation of such modalities will be optimal by implementing a common framework and methodology which give strategic coherence to this type of cooperation;

- it supports the introduction of an European model, relying on the principles of the framework strategy on information, aiming to improve the efficiency of law enforcement cooperation in the EU;

- it acknowledges the fundamental importance of the elaboration of the EU Organised Crime \& Threat Assessment to fight against Organized Crime (OCTA) by Europol and, as mentioned in the Hague Program, a mechanism to facilitate the elaboration of the OCTA will be adopted by the Justice and Home Affairs Committee and the collecting information process;

- it recognizes the potential of the European Union Law Enforcement Report to streamline information from member states and other European bodies to Europol aiming to develop OCTA and facilitating other Europol tasks to assist ministers in prioritizing after consulting the Working Party; work of European Police Chiefs;

- it admits the effectiveness of the coordination mechanism used by the Group of European Police Chiefs, including Europol, Migration and Customs, as well as other international bodies that have an important role to play in implementing the information framework strategy;

- the importance of effective judicial cooperation is recognized, especially that provided by Eurojust to support operational work; it calls on the United Kingdom and other future EU presidencies to make proposals on the European Crime Information Model, including the establishment of a working group of experts in the field.

In response to the challenge raised by the increasing number of cross-border crime, of organized crime in its extreme forms, in 1995 a program was launched so as to ensure political, military, economic and social stability in south-eastern Europe. It was based on consultations between the US Government and the EU, which ended with 8 programs covering various economic and social areas (transport; energy; environmental protection; commodity exchanges; small and medium enterprises). International analyses and documentation underlying this initiative have shown that, in most countries in the region, despite positive results in combating this scourge, difficulties in investigating and sanctioning such criminal acts, limited cooperation between agencies domestically and internationally, they have made the phenomenon increase in intensity and forms of manifestation.

The ever-expanding global market has made it possible to fully exploit the facilities of technological development and the benefit of the widening of national borders in the process of democratization and integration, providing a wide 
framework for transnational criminal networks. At the same time, the ways authorities engaged in the fight against this scourge are far from overcoming the multitude of financial, legislative or linguistic barriers, given that the activities of law enforcement institutions are still the exclusive prerogatives of national governments.

The current level of development of organized crime as phenomenon has made it increasingly clear that national efforts to combat it fail to keep pace with the constant evolution, ingenuity, danger and the power of penetration deeper and more specialized that characterizes the activity of criminal networks as a whole.

In all these years, Romania has sought to align itself to efforts made by the international community, contributing actively to the policies pursued in this direction, noting the proposal it made at a meeting of the Agenda Committee of the Political, Economic and Economic Stability Program in South-Eastern Europe on a project entitled "Preventing and Combating Cross-Border Crime".

The project initiated by our country's delegation, entitled "Preventing and Combating Cross-Border Crime", was approved in Geneva by the Agenda Committee of the Regional Center for the South East European Cooperation Initiative (SECI) on 15 April 1998, considered as a component part of the Program on Trade and Transport Facilities, and subsequently the Cooperation Agreement for the Prevention and Combating of Cross-Border Crime was concluded, in Bucharest on May 26, 1999, and ratified by Romania by Law no. 208/1999.

Negotiations between the participating countries lasted more than a year with the assistance of a group of experts from the main actors (USA, ICPOInterpol and the World Customs Organization (WMO)). These negotiations were finalized by a Framework Agreement called the "Agreement on Preventing and Combating Cross-Border Crime in South-Eastern Europe", in short, the "SECI Agreement" which entered into force on 1 February 2000.

The institutional framework, which would allow the functioning of the Regional Center of the Cooperation Initiative in South-Eastern Europe for combating cross-border crime, was created by O.U.G. no. 201/2000, as a natural continuation of the stages completed up to this date. Subsequently, this center, in short, the SECI Regional Center, was approved by Law no. 357/2001.

This international organization based in Bucharest (SECI Regional Center) brings together the representatives of the police and customs of the actors of this Agreement. The participants to the SECI Agreement are: Albania, Bosnia and Herzegovina, Bulgaria, Croatia, Greece, Macedonia, Moldova, Romania, Serbia and Montenegro, Slovenia, Turkey, Hungary, and those with observer status: Austria, Azerbaijan, Belgium, Canada, France, Georgia, Germany, Italy, Japan, the Netherlands, Portugal, Spain, the United Kingdom and the United States.

The basic concept of the SECI Agreement was the creation of a legal framework that could easily achieve cooperation between the countries in order to: prevent and combat cross-border organized crime (through data exchanges, 
technical assistance, cross experience, joint actions - "task force"); judicial cooperation in criminal matters (by increasing the flow of data, specific joint training and overcoming existing law enforcement issues in different states); providing assistance by the specialized agencies of the States involved in crossborder crime investigations; cooperation between bodies in the field of preventing and combating cross-border crime at both local and regional level, as well as at international level.

According to the provisions of the agreement, each member state shall set up a single contact point called the "national focal point". This process is perceptible in all fields of activity, it is appropriate with different forms of manifestation. It led to deep interactions between participants in the system of international relations, with direct and indirect effects, difficult to quantify and control, often falling outside the scope of a system of regulations, but also defined and generally accepted.

The successor to the South East Europe Cooperation Initiative (SECI) is the South East European Law Enforcement Center (SELEC), based in Bucharest. SELEC is an international organization whose main purpose is to intensify cooperation and coordination in preventing and combating cross-border crime, as well as providing support to member states.

„In 2006, a working group was set up to negotiate the draft Convention on the Establishment of the South-East European Law Enforcement Center - called the SELEC Convention. The text of the Convention was adopted in September 2009, in Thessaloniki, at the meeting of the Joint Cooperation Committee and signed at the meeting of the Bucharest Committee, December 2009. The SELEC Convention, which entered into force on October 7, 2011, is an international treaty ratified by all Member States". At the beginning of 2021, SELEC opens in Bucharest the new Operational Center equipped with state-of-the-art technology.

In our opinion, placing ourselves on the coordinates of an active observer, and restraining the evaluation strictly to the security issue, we can appreciate that the end of "Cold War" along with Soviet threat, the dynamics of international relations was marked by the transition from a bipolar world to a multipolar socalled "network world", characterized by the openness to cooperation and the extension of the fields of collaboration between the nuclei that make it and give consistency to the system. Proactive or reactive, the interdependence of the components of the international system requires the consolidation of new rules of "governance", which allow the evaluation, coordination and consensus of the activities of the subsystems that are manifested in their own formulas of expression on the international stage.

Consequently, nation-states must respond coherently to the security dilemma, which requires on the one hand securing the territory (implicitly closing it) and, on the other hand, formulating an adequate response to the problem of border permeability, a direct effect of the globalization process. 
Whether it is terrorism, organized crime, trafficking of human beings and drugs, illegal migration or the proliferation of WMD, unconventional threats follow the same pattern of globalization, so that, for example, the terrorist phenomenon becomes difficult to dissociate from secured funding organized crime activities, drug trafficking, illegal migration or attempts to possess and disseminate WMD. The direct reporting to the mentioned evolutions shows that along with the system of international relations a parallel system outcome, difficult to quantify but manifest of "unconventional threats", with actors, objectives, strategies, means of action and its own resources.

The decoding of the ways this unprecedented system works as well as the causes that lead to its development, aim at "visibility of the opponent" a sine-quanon condition, in the absence of which no response strategy can be designed coherently and risks not reaching objectives. Undoubtedly, in the effective fight against unconventional threats, there is a need to intensify international cooperation, cooperation managed and directed by managerial structures that develop viable long-term strategies, identify and eradicate causes of uncontrollable occurrence and evolution of these phenomena. Several initiatives are already included in this framework: the "Wider Middle East", the "Barcelona Process", the "Istanbul Cooperation Initiative", etc.

It must be emphasized that such cooperation strategies will have to lead to economic and political stabilization, a substantial reconfiguration of those areas, approached in terms of civilized entities and not geographical realities.

It goes without saying that identifying appropriate responses to this type of threat requires an extended framework of international and regional cooperation that attracts, together with the competent bodies, academia and civil society. This option will be able to lead to a better understanding of the factors responsible for the consequences of asymmetric threats, without focusing in a reductionist way on the negative effects that the later generate.

International cooperation must materialize both conceptually and practically. Thus, in our opinion, it will have to be finalized with the design of a new security architecture connected to the realities of the millennium beginning, taking into account the adaptable, diffuse and flexible nature of the new threats to international, regional and national security. The contribution of international bodies to the fight against terrorism is presented below.

The League of Nations (international body created during the Paris Peace Conference, by signing the Covenant of the League of Nation, on April 28, 1919) adopted:

Convention for the Prevention and Punishment of Terrorism, adopted on 16 November 1937, the first international legal instrument in this field. According to this convention, the following acts are considered acts of terrorism: acts committed intentionally, directed against life, body integrity, health or freedom of heads of state, those who exercise the prerogatives of the head of state, 
hereditary or designated successors of heads of state; spouses of the aforesaid persons; to persons with public functions or tasks, when the deed committed was based on the functions or tasks that these persons exercise; the intentional act consisting in the deterioration or destruction of public goods or of goods intended for public use; the act intended to endanger human lives by creating a common danger; the attempt to commit offenses under the above provisions; the act of producing, procuring and possessing or the act of being a supplier of weapons, ammunition, explosive products or harmful substances for the purpose of committing in any other country a crime of those presented.

The convention also provided for the inclusion in the criminal law of states of the following acts, if they were committed under conditions identical to the above: the act of association or agreement with terrorist organizations in order to commit the acts presented above; instigation of terrorist acts, when this has been followed by effect; the willful participation in terrorist acts and accession to a terrorist organization; any knowingly given assistance in carrying out a terrorist act.

For the purposes of the same Convention, the category of acts of terrorism includes one of the following criminal acts, not considered as political offenses, related to a political offense or inspired by political motives, such as: offenses contained in the Convention on the Suppression of Unlawful Capture of Aircraft, Convention signed on 16 December 1970 in The Hague; offences covered by the Convention for the Suppression of Unlawful Acts against the Safety of Civil Aviation, Convention signed on 23 September 1971 in Montreal; serious crimes which are directed against the life, body integrity or liberty of persons having measures of international protection, including diplomatic agents; offences involving abduction, hostage-taking or unlawful seizure; offences involving the use of weapons and ammunition or other improvised explosive devices (letters, packages, etc.), if their use poses a threat to persons; attempting to commit one of the above offences or taking part as an accomplice in the commission of one of those offences.

Convention for the establishment of an International Criminal Court, an organization whose results are still visible today.

The United Nations (through the Charter of the United Nations, signed at the San Francisco Conference on June 26, 1945, entered into force on October 24, 1945), adopted:

UN Convention on offences and certain other acts committed on aircraft was signed on 14 September 1963 in Tokyo (Romania joined to this Convention at the end of 1973 by Decree No. 627/1973);

Convention for the suppression of unlawful seizure of aircraft was signed on December 16, 1970, in Hague (Romania ratified this convention on April 19, 1972, by Decree No. 149). This convention was signed following the multitude of terrorist attacks that took place in 1970, against civil aviation - the 
most significant took place in Palestine (the concerted Palestinian attack), an attack that hijacked and destroyed 4 aircraft that belonged to several airlines.

According to the Convention, unlawful seizure of aircraft is a criminal offense committed by any person who boards an aircraft and in flight takes possession of that aircraft, exercises control over it or attempts to commit one of these acts, unlawfully and by violence or threat of violence or is the accomplice of a person trying to commit one of these acts.

Convention for suppression of illegal acts against civil aviation. This convention was signed on September 23, 1971, in Montreal, (Romania ratified this Convention on May 30, 1975, by Decree no. 66).

According to the convention, any person who unlawfully and intentionally commits an offence, such as: committing an act of violence against a person who is on an aircraft in flight, provided that the safety of the aircraft is endangered; the destruction and damage of an aircraft in service, causing damage to it and causing it to become unfit for flight, or damage to the safety of the aircraft; placing or contributing to the placement, by any means, of devices or substances on an aircraft in service, such devices or substances being capable of destroying or causing damage to the aircraft which is incapable of flight or is capable of endangering flight safety; destruction or damage to air navigation facilities or services or disruption of their operation if such acts are likely to endanger the safety of aircraft in flight; the transmission of information knowing that it is false, thus endangering the safety of aircraft in flight.

The same classification includes the one who tries to commit an act that represents one of the crimes presented above, if he is an accomplice in committing or attempting to commit one of these crimes.

On 24 February 1988, as a supplement to the Montreal Convention, was concluded the Protocol concerning the suppression of unlawful acts of violence at international civil aviation airports.

Convention regarding the prevention and punishment of crimes against persons enjoying international protection, including diplomatic agents. This convention was opened for signature on December 14, 1973, in New York. (Romania acceded to this convention in 1978, by Decree no. 254.) The category of such crimes includes the intentional act: murder, abduction or acts of any kind against the body integrity or liberty of persons benefiting from international protection; committing an attack, using violence, on official premises, personal residences or motor vehicles belonging to persons enjoying international protection and which by their nature may endanger their freedom and body integrity; threatening to commit this type of attack; attempting to commit such an attack; to be accomplice in such an attack.

International convention against taking of hostages, adopted in New York on December 17, 1979 (Romania acceded in 1990 by Decree-Law No. 11); According to the convention that regulates it, the taking of hostages is the act of 
any person or group of persons who kidnaps or detains a person and threatens to kill and injure him, in order to coerce certain parties (state, international organization, group of people, official persons, etc.), to perform or not to perform an act, this being an explicit or implicit condition for the release of the hostage. Also, any person attempting to commit this act or is an accomplice of an individual who commits or attempts to commit such an act (as was the tragically case of the Lufthansa aircraft, in 1977, hijacked at the airport from Mogadishu; Iran's hostage crisis in 1979; also, perpetration an offense within the meaning of that Convention.

UN Convention on the physical protection of nuclear material, signed on 3 March 1980 in Vienna;

UN Convention to combat illegal acts against the safety of maritime navigation, signed March 10, 1988, in Rome;

UN Convention on the marking of plastic explosives for detection, signed on 1 March 1991 in Montreal;

The International Convention for the Suppression of Terrorist Bombings, signed on 15 December 1997;

International Convention for the Suppression of the Financing of Terrorism, adopted in New York on December 9, 1999 (signed also by Romania);

Convention on the Blocking of any Support for Terrorist Networks, Financial and Logistical, signed on 1 October 2001 in New York.

An important step in the fight against terrorism was the adoption by the UN General Assembly of Resolution no. 3034 of December 18, 1972, ${ }^{28}$ entitled: "Measures for the prevention of international terrorism that endanger or destroy innocent human lives or that carry out fundamental freedoms and the study of the causes that generate forms of terrorism and acts of violence that originate in poverty, disappointment, dissatisfaction and despair and which causes some people to sacrifice human lives, including their own lives, in an attempt to bring about radical change" as well as UN Security Council Resolution no. 1373 of 2001, which refers to the fight against international terrorism.

Euro-Atlantic (regional) organizations:

The Council of Europe $^{29}$ adopted the European Convention on the Suppression of Terrorism in Strasbourg on 27 January 1977.

NATO - The Ministerial Meeting of the North Atlantic Council, which adopted the Declaration on NATO's Response to Terrorism in Brussels on 6 December 2001 (Prague Summit of 21-22 November 2002, adopting the CounterTerrorism Action Plan of the Euro-Atlantic Partnership"). ${ }^{30}$

\footnotetext{
${ }^{28}$ https://unispal.un.org/DPA/DPR/unispal.nsf/85255db800470aa485255d8b004e349a/69cb600fbde9eddd $852570840050 \mathrm{c} 345$ ?, valid at 06.06.2021.

${ }^{29} \mathrm{https} / / / \mathrm{www}$. coe.int/en/web/portal, valid at 06.06.2021.

${ }^{30} \mathrm{https} / / / \mathrm{www}$. nato.int/, valid at 06.06.2021.
} 
The OSCE (regional organization to support Member States in implementing UN instruments) ${ }^{31}$ adopted the following documents: the Helsinki Final Act and the Final Acts of the Madrid Meetings in 1983 and Vienna in 1998; Conference for Security and Co-operation in Europe, Paris Charter for a New Europe, Paris, 1990; Istanbul OSCE Summit, Charter for European Security, 1999; OSCE Ministerial Council, Action Plan to Combat Terrorism, held on 3-4 December 2001 in Bucharest.

The Organization of American States adopted the Convention on the Prevention and Punishment of Acts of Terrorism Representing Crimes Against Persons (Kidnapping, Murder, Assault, etc.), as well as acts of force related to such crimes when such acts have international repercussions, Washington, February 1971 (the first regional convention on this matter).

Perceived as a necessity, since 1994 with the launch of the Partnership for Peace, cooperation can be a viable solution, only insofar as the stage of theoretical questions is overcome, designing concrete measures to optimize the management of international cooperation, sound decisions on clear and realistic strategies. They must subsume concrete directions and modalities of cooperation that take into account the domino effect of globalization of international relations, in order to avoid the spread of negative implications of unconventional threats on regions that have demonstrated "relative immunity to various unconventional threats".

At the international community level, there is currently a consensus on how unconventional threats are perceived. Cooperation in combating these threats must be achieved, but there is consensus on how to respond (preventively or preemptively), as well as the legitimacy of retaliatory actions, given that, to date, the UN is the only authority in the field.

As such, from this perspective, the efficient management of cooperation implies the efficiency of the world organization, the use of the framework offered by it to lead to the constructive elimination of differences of opinion, the flexibility of existing structures, in the sense of connecting them to new security climate parameters and strengthening the universal vocation of the UN.

In conclusion, cooperation is all the more necessary as the multilateral approach requires coherence in the conception of strategies, streamlining existing security structures, therefore to eliminate the possibility of inefficient duplication or undesirable overlap and, implicitly and explicitly, inefficient consumption of resources. At the same time, depending on the skills and experience in the specific field of action of the actors involved in global security management, international cooperation will have to set concrete priorities and modalities at some point, anticipating trends that may manifest later.

\footnotetext{
${ }^{31}$ https://www.osce.org/, valid at 06.06.2021.
} 


\section{BIBLIOGRAPHY}

- National Defence Strategy 2020-2024,,Together for a safe and prosperous Romania in a world markedby new challenges" Romania Presidential Administration, Bucharest, 2020; https://www.presidency.ro/files/ userfiles/National_Defence_Strategy_2020_2024.pdf

- National Strategy to Fight Organized Crime In The Period 20042007|Decision 2209/2004, http://www.just.ro/strategia-nationala-impotrivacriminalitatii-organizate-2021-2024/

- Cîrnici Luminița Ludmila, European terrorism and the impact on national security, Top Form Publishing House, Bucharest, 2017.

- Glen E. Howard and Matthew Czekaj, Russia"s Military Strategy and Doctrine, The Jamestown Foundation, Wahinngton, DC.

- Internatiobnal Rewiew of the red Cross, Children and War, Volumec 101, number 911, Cambridge University Press.

- https://www.mae.ro/node/1498, accessed on 20.02.2021.

- https://www.coe.int/en/web/portal, valid at 06.06.2021.

- https://www.nato.int/, valid at 06.06.2021.

- https://www.osce.org/, valid at 06.06.2021.

- https://unispal.un.org/DPA/DPR/unispal.nsf/85255db800470aa485255d8b00 4e349a/69cb600fbde9eddd852570840050c345?OpenDocument 